\title{
The Pioneering and Unknown Stereotactic Approach of Roeder and Orthner from Göttingen. Part I. Surgical Technique for Tailoring Individualized Stereotactic Lesions
}

\author{
Wolfgang Hamel ${ }^{\mathrm{a}}$ Johannes A. Köppen ${ }^{\mathrm{a}}$ Marwan Hariz $^{\text {c,d }}$ Paul Krack \\ Christian K.E. Moll ${ }^{\mathrm{b}}$
}

Departments of a Neurosurgery and ${ }^{\mathrm{b}}$ Neurophysiology and Pathophysiology, University Medical Center HamburgEppendorf, Hamburg, Germany; ' Unit of Functional Neurosurgery, UCL Institute of Neurology, London, UK;

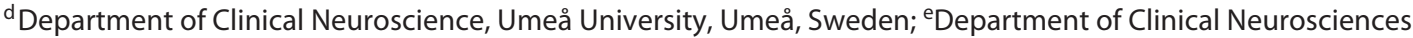
(Neurology), Faculty of Medicine, University of Geneva, Geneva, Switzerland

\section{Key Words}

History · Stereotactic surgery · Stereotactic lesioning · Pallidotomy $\cdot$ Ventriculography $\cdot$ Targeting $\cdot$ Brain atlas

\begin{abstract}
During the 1950s through the 1970s, Hans Orthner and Fritz Roeder, two German neurologists from Göttingen, developed a sophisticated technique to perform functional stereotactic surgery with outstanding accuracy. They introduced direct air ventriculography performed in the same surgical session as the ablative stereotactic procedure. For individualized surgical targeting, Orthner prepared a stereotactic atlas ( $>60$ brains) with an ingenious brain-slicing device, the Göttinger macrotome. Brains were grouped based on similarity of six different head and ventricle measurements. A brain cluster representing the best match for a patient was selected for stereotactic targeting. Stereotactic lesions were tailored in an individual manner and shaped by stringing together multiple small coagulations following in-
\end{abstract}

traoperative test stimulation. This was achieved from a single probe trajectory by using well-engineered string electrodes with calibrated curving and involved laborious calculations. Only high-frequency thermocoagulation was regarded as appropriate for lesioning. With this meticulous technique, the most advanced stereotactic procedures were performed, including bilateral pallidotomy that ultimately could be restricted to the ansa lenticularis and ventromedial hypothalamotomy, the most delicate stereotactic operation performed to date. Outside Göttingen, this technique has only been used by Prof. Dieter Müller in Hamburg, Germany. This elaborate stereotactic approach is widely unknown and deserves to be discussed in a historical context.

(c) 2016 S. Karger AG, Basel

Dedicated to Prof. Dr. Dieter Müller, Head of Functional Neurosurgery at the University Hospital Hamburg-Eppendorf between 1972 and 2002.

\section{KARGER}

E-Mail karger@karger.com

www.karger.com/sfn (c) 2016 S. Karger AG, Base

$1011-6125 / 16 / 0944-0240 \$ 39.50 / 0$
PD Dr. Wolfgang Hame

Klinik für Neurochirurgie, Universitätsklinikum Hamburg-Eppendorf Martinistrasse 52

DE-20246 Hamburg (Germany)

E-Mailw.hamel@uke.de 


\section{Introduction}

Stereotactic surgery for the treatment of psychiatric and neurological disorders was pioneered by Spiegel and Wycis [1]. In their monograph from 1962, they mentioned groups from different countries who had also adopted stereoencephalotomy, and Fritz Roeder and Hans Orthner, two professors of neurology from Göttingen, range among the most frequently cited authors [2]. They were the first to alleviate hemiballism by pallidotomy without compromising voluntary movements [3]. Furthermore, they successfully performed some of the most demanding stereotactic procedures, such as bilateral pallidotomy $[4,5]$ and the first medial mesencephalotomy [6], and, ultimately, they introduced ventromedial hypothalamotomy $[7,8]$. At its peak, the Göttingen group was highly renowned and was referred patients from neighboring countries. The achievements of Roeder and Orthner were based on a unique and unsurpassed approach enabling individualized stereotactic planning and tailored lesioning in a way that differed from targeting at other centers (summarized in table 1). This paper describes the practice of the Göttingen functional stereotactic school as it was developed in its historical context.

\section{Ventriculography}

In the 1950s and 1960s, hundreds of patients suffering from various neurological or psychiatric disorders were treated with sometimes imprecise aiming tools or approaches involving more or less free-hand or semistereotactic maneuvers [9-13]. Clinical results were somehow inconsistent, and the surgical risks were not negligible. Roeder and Orthner pointed out that only a few stereotactic systems exhibited a high enough degree of accuracy considered as absolutely necessary for interventions in the brain [14]. In their opinion, the systems of both Riechert [15-17] and Leksell [18] fulfilled this requirement, and they chose a system that enabled the surgeon to simulate targeting on a phantom $[14,16,17]$. This was possible with the system developed by Riechert and Wolff [15], which ranked among the most accurate stereotactic systems and which stood the test of time (mounting of frame is shown in fig. 1a). Roeder was well acquainted with the system by Riechert, who gave him important advice [3]. In Göttingen, the Riechert system was adapted to special needs (e.g. steering of probes) in cooperation with the workshop of the Max Planck Institute.

Stereotactic Approach of Roeder and Orthner
Table 1. Specifics of the stereotactic approach of Roeder and Orthner

\begin{tabular}{|c|c|}
\hline Problem & Measures \\
\hline $\begin{array}{l}\text { Patient } \\
\text { comfort }\end{array}$ & $\begin{array}{l}\text { Air ventriculography } \\
\text { Ventriculography in general anesthesia } \\
\text { Single-day surgery }\end{array}$ \\
\hline $\begin{array}{l}\text { Stereotactic } \\
\text { precision }\end{array}$ & $\begin{array}{l}\text { Choice of Riechert's system (Freiburg) } \\
\text { Direct ventriculography in supine position } \\
\text { Ventriculography and procedure in same position } \\
\text { No replotting of X-rays }\end{array}$ \\
\hline $\begin{array}{l}\text { Anatomical } \\
\text { precision }\end{array}$ & $\begin{array}{l}\text { Orthner's stereotactic brain atlas ( }>60 \text { brains) } \\
\text { Accurate slicing (Göttinger macrotome) } \\
\text { 'Head-ventricle formula' } \\
\text { Individual match with best 'model brain } \\
\text { combination' } \\
\text { Individual lesion tailoring (e.g. ansa lenticularis) } \\
\text { Exact calculations (including tip of string } \\
\text { electrode) }\end{array}$ \\
\hline $\begin{array}{l}\text { Surgical } \\
\text { procedure }\end{array}$ & $\begin{array}{l}\text { Exceptional use of (isolated) string electrodes } \\
\text { Focused intraoperative stimulation and mapping } \\
\text { Only radiofrequency thermolesioning } \\
\text { Shaping of lesions (multiple small lesions) }\end{array}$ \\
\hline $\begin{array}{l}\text { Reduction of } \\
\text { complications }\end{array}$ & $\begin{array}{l}\text { Direct ventriculography with air } \\
\text { Focused test stimulation (mapping of internal } \\
\text { capsule and optic tract) } \\
\text { Mode of lesioning (see above) } \\
\text { Coagulation program from a single trajectory } \\
\text { Avoidance of internal capsule } \\
\text { Use of string electrodes }\end{array}$ \\
\hline $\begin{array}{l}\text { Documen- } \\
\text { tation }\end{array}$ & $\begin{array}{l}\text { Detailed case by case descriptions } \\
\text { Careful documentation of effects and } \\
\text { complications } \\
\text { Surgery and clinical assessment by neurologists }\end{array}$ \\
\hline
\end{tabular}

In the 1950s encephalography was introduced that required the introduction of air via the lumbar or suboccipital route. However, air accumulating in the peripheral CSF spaces resulted in suboptimal images due to blurred delineation of the ventricles or brain shift [19, 20]. Even in the most experienced hands extracerebral air collections were observed in $13 \%$ of the patients, as shown in an evaluation of 1,800 patients operated on in Freiburg between 1952 and $1962[19,20]$.

Roeder and Orthner were among the first to introduce direct air ventriculography performed on the day of surgery for stereotactic imaging for target coordinate calculations (fig. 1c, d) [4]. Air ventriculography had been described by Dandy [21] but, to the best of our knowledge, not employed in stereotactic neurosurgery until then. In

Stereotact Funct Neurosurg 2016;94:240-253 
their inaugurating report of medial mesencephalotomy for intractable pain, Roeder and Orthner [6] shifted from using lumbar encephalography to air ventriculography: whereas the first patient (date of surgery: Feb 14, 1959) had received a suboccipital puncture for encephalography, in the second case (date of surgery: Nov 4, 1959) air ventriculography was performed through direct ventricular puncture.
Talairach [22] was probably the first to perform ventriculography for stereotactic procedures, but he relied on positive contrast media. However, Roeder objected to the use of positive contrast media and adhered to the use of air, which he regarded as sufficient and less hazardous. Indeed, ependymal and arachnoidal irritation, iodine hypersensitivity, epileptic seizures, aqueductal stenosis, and other complications had been reported with the use of, for
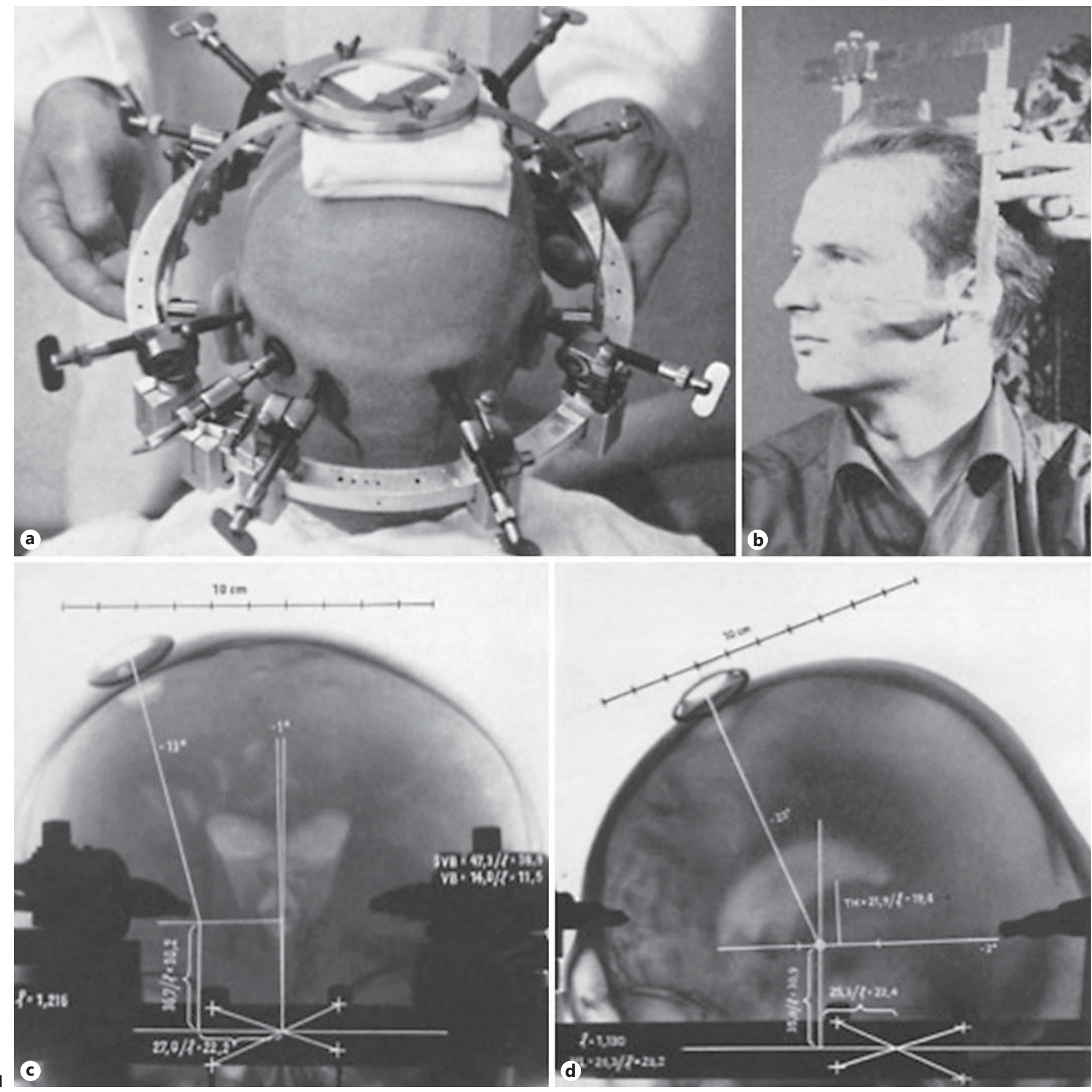

(For legend see next page.) 
example, Lipiodol $[4,23-26]$. It was for this reason that Spiegel and Wycis [2] eventually opted for the use of the more modern pantopaque (Myodil) that was better tolerated. Levy [27] reported that in $93 \%$ of patients air ventriculography was sufficient and in only $7 \%$ of their cases had they to use contrast media. This was supported by the experience of others $[28,29]$. With the availability of less toxic contrast media towards the end of 1960s these had also been used in selected cases in Göttingen and Hamburg, for example, for hypothalamotomy and when the third ventricle proved to be too narrow for clear definition of commissures on air ventriculograms [30]. Air ventriculography, however, remained the first choice.

In 1967, van Manen [28], citing Orthner and Roeder [4], wrote: 'If a lumbar or suboccipital injection is unsuccessful, the air can be injected directly into the ventricular system, with or without some slight positive pressure' which is a hint that this had not been a generally adopted procedure at that time. In 1973, Van Buren and Ratcheson [25] stated that 'Visualization has been reliable and without serious complications apart from some headache, which, in general, is less severe than after pneumoencephalography. Positive-pressure air ventriculography is the most generally satisfactory and least hazardous method known to the authors for demonstrating stereotaxic landmarks'. Van Buren only cited personal communications with Bravo (1968) and Bertrand (1969) [25]. Furthermore, he did not cite Calvin and Coe [29], who, several years after Roeder and Orthner, had published a single-stage technique similar to the one used in Göttingen that included pressure monitoring. Siegfried [31] mentioned direct ventriculography, and again, the only reference is given to Bertrand and Martinez [32]. Bertrand started with direct air ventriculography around the same time as Roeder. In the beginning, however, Bertrand used

Fig. 1. a Mounting of the stereotactic frame aided by a bearing arc carrying the weight of the frame and cushioned with a gauze pad because it was easier to adjust the frame when supported. Two springy bolts ('ear olives') were introduced into the external auditory canal to help the alignment of the frame and to minimize yaw and tilt. After noninvasive clamping with blunt screws the frame was fixed with 6 sharp pins to the skull [4]. Later, the frame was mounted in halogen-based general anesthesia directly preceding ventriculography to increase patient comfort. $\mathbf{b}$ The height of the head ('Ohrhöhe') was measured from the external auditory canal with the help of a caliper rule. In addition, the width and length of the head were obtained [35]. c, d Direct ventriculography with air [coronal (c) and sagittal (d)]. After burr hole trephination a Cushing needle was inserted into the frontal horn of the ventricular oxygen and introduced this from the deepest point without pressure. This approach had the advantage of avoiding slight pressure but involved repositioning of the head. Later, he apparently performed air ventriculography in a similar manner as in Göttingen [33].

Leksell had also started with direct air ventriculography around the same time as Roeder. Laitinen [34] evaluated ventriculograms of Leksell's pallidotomies performed at the Sophiahemmet hospital from 1958 to 1962. Both lumbar encephalography as well as air ventriculography were mentioned, and figure 1 of his study appears to represent a direct air ventriculography from 1960. Discussions occurred between Leksell and Roeder about the optimal amount of CSF to be withdrawn (apparently somewhat less in Göttingen than in Sweden) and whether this should be performed in general anesthesia [D. Müller, pers. commun.].

Although direct air ventriculography was much better tolerated than lumbar or suboccipital encephalography $[25,29]$, with the latter often provoking headache, nausea, vomiting, confusion, restlessness, and even circulatory collapse, Roeder attempted to improve patient comfort further. He performed mounting of the frame and ventriculography under halothane-based general anesthesia [35]. The anesthesiological procedure had been published in a paper by Fischer et al. [36] from the Department of Anesthesiology of the Göttingen University Hospital, the first centralized anesthesiology department in Germany. The paper was not coauthored by Roeder or Orthner.

Since Roeder performed ventriculography on the same day as the therapeutic procedure, the stereotactic frame remained on the head in the same position both for ventriculography and ablative surgery, resulting in a higher accuracy. By adopting a single-day approach and by working with exactly congruent beam projections, two

system, and 5-20 $\mathrm{ml}$ of CSF was withdrawn (in older patients with 'negative' pressure no CSF) and was exchanged for 25-35 $\mathrm{ml}$ of air being introduced with slight pressure to delineate the ventricles down to the aqueduct. During air injection the head was auscultated with a stethoscope, and later this maneuver was supported by fluoroscopy. Whereas a piping sound could be perceived when air entered the aqueduct, a sparkling sound indicated air already exiting into the peripheral CSF spaces. When X-rays of sufficient quality had been obtained the intraventricular air was exchanged for the preserved CSF. Ventricular ('inner') measurements included the length of the third ventricle, width and angles of the lateral ventricles, and the height of the thalamus measured $12 \mathrm{~mm}$ behind the posterior rim of the anterior commissure [4]. 
significant sources of errors could be avoided: (1) those associated with readjustment of the frame to the central ray and (2) those associated with the realignment of Xrays, which was required if a nonstereotactic encephalography or ventriculography had been performed on a previous day.

In 1963, Levy, who had been trained in Freiburg, started to perform ventriculography in a similar manner as in Göttingen [27]. He explained that initially 'the two-stage procedure was adopted after warnings from the Freiburg team about complications arising after pneumoencephalography in Parkinsonians' [27]. Until after 1973 the Freiburg group recommended such staged procedures. They referred to the great distress and repeatedly confused states following lumbar encephalography (with air or helium) in the often old and fragile Parkinsonian patients $[20,37]$.

A staged procedure required the realignment of the presurgical (pneumoencephalographic) X-ray and the stereotactic X-ray. Levy [27] wrote that '... it was found that replotting with the aid of bone reference points sometimes caused errors in excess of the permissible $1 \mathrm{~mm}$ '. This problem was also emphasized by others, for example, van Manen [28]. Similarly, Laitinen [38], in his memoir published in 2004, reported on his 4-month visit to Freiburg and considered the Freiburg technique of separating ventricular imaging from the surgical procedure as not precise enough. In addition, presurgical lumbar pneumoencephalography was performed in the sitting position, whereas surgery took place in a prone position. It had been demonstrated that subdural air collections (moving frontally after repositioning) could lead to a significant shift (several millimeters) of deep brain structures, such as the pineal gland $[19,20]$. Over time the advantages of the one-stage approach became evident [39].

\section{Orthner's Stereotactic Brain Atlas}

Orthner, who was director of the Department of Neuropathology at the University of Göttingen, had a longstanding interest in brain anatomy and quantitative brain research and had been searching for an ideal brain-slicing instrument for many years. At the time when the atlas of Schaltenbrand and Bailey [40] was being prepared, a macrotome was available: the Edinger macrotome [41]. Orthner wondered whether Schaltenbrand and Bailey had been aware of this macrotome since for the preparation of the atlas a device had been constructed that was similar to the Edinger macrotome, but the Edinger macrotome had not been mentioned $[42,43]$. Orthner had inspected the Edinger macrotome and other brain-slicing devices (e.g. a particular knife developed by B. Ostertag at the Kaiser Wilhelm Institute in Munich). However, he found all of them not suited for stereotactic and quantitative brain analysis [42] (also see online suppl. material, www. karger.com/doi/10.1159/000448080). This issue had also been noticed by Van Buren and Maccubbin [44], who stated that 'although practically no mention of this appears in the literature, possibly the most difficult point in preparation of macrosections of the brain lies in achieving sections at accurately determined intervals'. Orthner agreed with Amador et al. [43], who, in the methods section of the atlas of Schaltenbrand and Bailey [40], pointed out that slices with an intended thickness of $5 \mathrm{~mm}$ may have an actual thickness of between 3 and $7 \mathrm{~mm}$. Stereotactic surgeons are aware that the slice thickness in the Schaltenbrand atlas varies (sectioning could not be performed at exact intervals).

Orthner came to the conclusion that the slicing of brains with knives in general is inaccurate even if they are well guided by notches. He had the idea to use a device similar to an egg slicer. With this apparatus the brain would be cut by strings made from steel (mandolin E string). According to this principle, a novel apparatus was manufactured by the Zentralwerkstatt Göttingen $\mathrm{GmbH}$, termed the 'Göttinger macrotome' (fig. 2a, b) [42, 45, 46]. Several years later, Slaughter and Bashold [47], having also recognized the problem of exact slicing, designed an instrument that was engine driven and produced $5-\mathrm{mm}$ macrosections by ultrathin blades. In their technique the brain was radiographically aligned.

The protocol for brain preparation and use of the Göttingen macrotome has been summarized (see online suppl. material). A commissure-based coordinate system as introduced by Talairach [22] was adopted with reference to the posterior rim of the anterior commissure $(\mathrm{x}=0$; $y=0 ; z=0)$ and the intercommissural plane. Immersion fixation was found to be more reliable than intravasal fixation as used, for example, by Spiegel and Wycis [2] and Talairach et al. [23]. Interestingly, Van Buren and Maccubbin [44] as well as Slaughter and Bashold [47] later came to the same conclusion as Orthner. Both groups independently worked out procedures that resembled the one used in Göttingen with respect to (1) immersion fixation, (2) suspending brains from the basilar artery, and (3) embedding brains before slicing.

In 1966, the atlas contained $>50$ normal brains [14]. In a paper published later, the authors referred to a number of 65 model brains [48]. This represents one of the largest 
Table 2. The procedures performed with 'model brain combinations' (MBC) and their anatomical references

\begin{tabular}{|c|c|c|}
\hline Procedure & $\begin{array}{l}\text { MBC, } \\
\mathrm{n}\end{array}$ & Anatomical reference \\
\hline Pallidotomy & 14 & medial border of internal pallidum \\
\hline Basolateral thalamotomy & 6 & lateral border of motor thalamus \\
\hline Dorsomedial thalamotomy & 6 & lateral border of dorsomedial nucleus \\
\hline Basomedial thalamotomy & 4 & basal border of medial thalamus \\
\hline Campotomy & 5 & $\begin{array}{l}\text { dorsolateral border of red nucleus at largest } \\
\text { diameter }\end{array}$ \\
\hline Hypothalamotomy & 5 & optic tract and tuber cinereum \\
\hline Fornicotomy & 3 & $\begin{array}{l}\text { borders of fornix } 2 \text { and } 5 \mathrm{~mm} \text { above } \\
\text { midcommissural point }\end{array}$ \\
\hline Commissurotomy & 4 & borders of anterior commissure \\
\hline Mesencephalotomy & 4 & borders of dorsal midbrain tegmentum \\
\hline Amygdalotomy & 6 & depth of fissura hippocampi at amygdala \\
\hline Cingulotomy & 5 & corpus callosum/lateral ventricle \\
\hline Frontal leukotomy & 7 & defined points at basal surface of frontal cortex \\
\hline Corpus mamillare & 9 & center of corpus mamillare \\
\hline
\end{tabular}

stereotactic atlases that had ever been prepared, and one regrets that the actual atlas with all model brains and values had not been published. Unfortunately, we are not in possession of the whole atlas, which had been disposed of after Orthner's retirement [Mrs. A. Orthner, pers. commun.].

This atlas was not only motivated by the benefit it would bring to stereotactic neurosurgery but also by Orthner's neuropathological interest in investigating quantitative changes in different areas of the brain in various neurological and psychiatric diseases. For example, in a first analysis of 37 normal brains he found that the volume of the pallidum was slightly larger in males $(>1.65$ $\left.\mathrm{cm}^{3}\right)$ than in females $\left(>1.40 \mathrm{~cm}^{3}\right)$ [49]. The volume correlated with the volume of the hemispheres. Later, he presented data of 106 brains from patients suffering from various neurological and psychiatric disorders [50]. For example, in Parkinson's disease the volume of the pallidum relative to the volume of the respective hemispheres was increased compared to control brains $[50,51]$.

\section{Stereotactic Planning}

Roeder and Orthner emphasized that the anatomical localization of the exact target for an individual patient had become the most critical issue, as they had already been working with one of the most precise stereotactic devices (Riechert's system), and had improved technical aspects of the procedure (direct ventriculography on the day of surgery and the same position for imaging and surgery) [35]. Similarly, Spiegel wrote: '... so that chiefly two problems face us at present: first, the uncertainties of localization in vivo that are due to the individual variability in the coordinates of the various subcortical structures, and second, the choice of the optimal method of producing subcortical lesions'. [52].

Orthner and Roeder found that the location of stereotactic targets cannot be predicted with sufficient accuracy when this is based on (proportional) correction algorithms as proposed by others $[23,28,53]$. This concern was supported by anatomical variation studies that had failed to generate a formula that was better than average brain coordinates to predict the location of a point of interest in the brain relative to suitable landmarks $[44,54]$. The limitations of proportional factors as used by Hassler and Riechert was also pointed out by Spiegel [footnote in $52]$. Spiegel and colleagues $[55,56]$ had also performed thorough brain variation studies and found that the position of the pallidum could neither be inferred reliably from the width of the brain nor from the width of the third ventricle. This is why Spiegel suggested the use of safety lines instead [2]. These, however, had the disadvantage of constricting and possibly shifting the target area.

To accomplish best possible individualized stereotactic planning, Orthner's atlas was used in a unique manner [described in detail in 4-6, 14, 30, 35] (see online suppl. material). The selection of merely a single brain from the 
Table 3. Stereotactic lesions performed at the University Hospital Hamburg-Eppendorf (1972-1994)

\begin{tabular}{lr}
\hline Procedure & $\mathrm{n}$ \\
\hline Thalamotomy & 207 \\
Pallidotomy & 54 \\
Amygdalotomy & 48 \\
Cingulotomy & 32 \\
Ventromedial hypothalamotomy & 28 \\
Mesencephalotomy & 9 \\
Posterior hypothalamotomy & 7 \\
\hline
\end{tabular}

Indications were Parkinson's disease $(\mathrm{n}=127)$, dystonia $(\mathrm{n}=$ $57)$, tremor $(n=42)$, 'sexual deviation' $(n=28)$, pain $(n=24)$, epilepsy $(n=23)$, obsessive compulsive disorder $(n=23)$, other movement disorders $(\mathrm{n}=18)$, autoaggressivity $(\mathrm{n}=14)$, anxiety neurosis $(n=11)$, Huntington's chorea $(n=9)$, other psychiatric disorders $(n=4)$, and addiction $(n=3)$.

atlas was regarded as too inaccurate for stereotactic planning. To incorporate some averaging, brains from the atlas were clustered based on similarity. In fact, Spiegel emphasized the advantage of such grouping of brains [52]. Orthner was mentioned in this paper, and we assume that Spiegel was aware of Orthner's atlas since Spiegel and the Göttingen group were in contact [Dr. Philip Gildenberg, pers. commun.]. Eventually, 28 'model brain combinations' were available. These have also been used for all cases of stereotactic lesioning in Hamburg (1972-1994), the only other stereotactic center having used this approach. Table 2 gives a summary of the procedures with 'model brain combinations' and their anatomical references. The procedures performed in Hamburg have been summarized in table 3.

Each group of brains ('model brain combination') consisted of (at least) 3 brains from the atlas being similar according to the so-called 'head-ventricle formula'. Some brains from the atlas were included into more than one 'model brain combination'. The 'head-ventricle formula' included three 'outer' (head) measurements (width, length, and height of the head), where the latter was measured with a particular caliper rule from the ears ('Ohrhöhe') (fig. 1b). In addition, three 'inner' (ventricle) measurements were used (width and angles of the lateral ventricles, the length of the third ventricle, and the height of the thalamus measured $12 \mathrm{~mm}$ behind the posterior rim of the anterior commissure) (fig. 1c, d).

The inclusion of three cranial measures into the 'headventricle formula' may be difficult to understand from a present-day perspective. However, at that time cranial landmarks (and pineal calcifications) still played an important role, and even surgeons dedicated to truly stereotactic approaches continued to base part of their planning on these $[12,34]$. For example, in the procedures performed between 1958 and 1962, Leksell apparently adjusted the laterality of his target according to the width of the skull [34]. At the same time, surgeons had also been aware of the limitations associated with the use of cranial measures. For example, Talairach had found that the length of the skull does not correlate with the length between both commissures [23].

Over the years, priority was given to the 'inner' (ventricle) measurements [D. Müller, pers. commun.]. Although not formally included into the 'head-ventricle formula', the width of the third ventricle was also taken into account (entered on the planning protocol shown in online suppl. fig. 5) and gained increasing attention [30; D. Müller, pers. commun.]. On the other hand, the width of the third ventricle does not alone explain the laterality of a target, an issue that is still unresolved. Orthner and Roeder had realized that by giving priority to ventricle measurements for selecting the best 'model brain combination', relevant information from head measurements might be missing. In particular, there was concern with regard to the width of the brain, representing another important factor for the laterality of a target, although only the width of the head could be measured. To this end, a formula had been developed to adjust lateral coordinates from the Orthner atlas (denoted ' $y$ ') to patients according to factors based on the width of the third ventricle ( $\mathrm{fl}$ ) and the width of the head (f2; see online suppl. fig. 6).

With respect to surgical deep brain targets, average coordinates for appropriate reference structures had been determined for each 'model brain combination' (fig. 2d). For example, fourteen 'model brain combinations' served as a database for mapping the medial border of the internal pallidum. To visualize the actual variability reflected by these 'model brain combinations', current image analysis tools have been employed (shown and explained in fig. 2e, f). First of all, it was surprising to what extent the 'model brain combinations' covered a significant degree of variation. Most striking, however, was the high resolution and even distribution with which variability was reflected by these 'model brain combinations' (fig. 2e, f). The medial border of the internal pallidum is shown for both the left and right side as the coordinates of most 'model brain combinations' differed between both hemispheres. This is in accordance with Orthner's findings that the volume of the left pallidum relative to the volume of the hemispheres was slightly larger than 

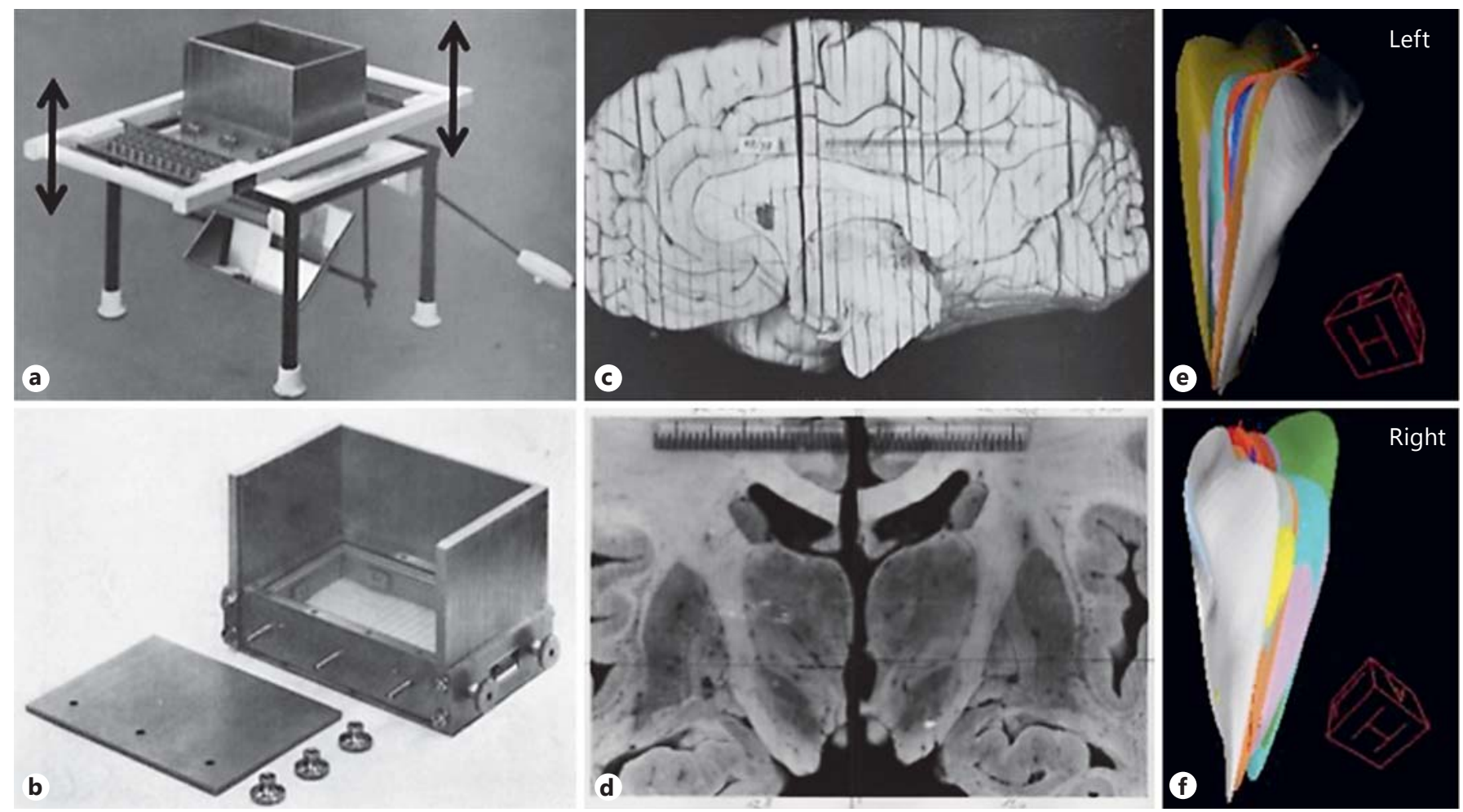

Fig. 2. a The 'Göttinger macrotome' constructed by the Zentralwerkstatt Göttingen $\mathrm{GmbH}$ based on the conception of Orthner. Arrows indicate the movement direction of the sectioning lyra. The mode of operation is explained in the text. $\mathbf{b}$ View into the lamellated box containing a base from glass with a carved grid [46]. c Lamellated brain consisting of slices of exactly $4 \mathrm{~mm}$ in thickness obtained with the 'Göttinger' macrotome. d Example of a 4-mm brain slice from Orthner's atlas (brain No. 174/58). Borders of relevant structures were delineated and measured where indicated [46]. e, $\mathbf{f}$ Medial border of the internal pallidal segment as deter- mined from Orthner's brain atlas. Each layer represents the average of 3 (in one case 4) brains that had been grouped together by Orthner based on the 'head-ventricle formula' generating distinct 'model brain combinations'. For the pallidum, the medial border was evaluated in 14 such 'model brain combinations' (representing a total of 43 brains). The coordinates were read from Orthner's spreadsheets (as shown in online suppl. fig. 8). These were plotted to generate meshes that were smoothed using open-source-based tools developed by one of the authors (J.A.K.). on the right side [49]. These pioneering findings of that era about asymmetries in pallidal measurements between hemispheres, and their implications for stereotactic targeting, have eventually been confirmed by others using detailed measurements on dedicated MRI sequences [57].

With these data it was possible to tailor an individual coagulation program. For each target (e.g. the pallidum) a favorable position for the carrier probe was indicated. Actual prelesional test stimulations and coagulations were accomplished from a single trajectory. This involved complex calculations as detailed by Orthner et al. $[4,30]$ and presented in online supplementary figures 7 and 10 . The following had to be taken into account: first, the position of the tip of the carrier probe ('S') as well as the sagittal $(\alpha)$ and lateral $(\beta)$ angles used for its introduction (online suppl. fig. 7,10 ) and second, the type and curvature of the string electrode used, which was checked and calibrated at regular intervals (distances $\mathrm{k}$ and $\mathrm{l}$; online suppl. fig. 9). This generated settings that were performed within the same trajectory: (1) the direction in which the string electrode was to be extruded from the rotatable probe (angle $\varphi$; defined in clockwise direction relative to the plumb line; online suppl. fig. 5); (2) the distance ('M') the electrode was to be lowered from the tip of the probe, and (3) the depth of the probe ('S'), which had to be retracted or advanced a few millimeters. Thus, no additional probe trajectory was inflicted on the patient. Before the advent of calculators, spreadsheets for frequently used angles containing about 300,000 values were used to determine stereotactic settings (prepared by W. Sendler, Max Planck Institute, Göttingen; see online suppl. material). 
Fig. 3. a Specifications of 2 types of isolated string electrodes with gearing mechanism [5]. Note the scale for lowering of the electrode [8]. Individual electrodes exhibit slight deviations in curvature that may change over time. Calibration curves $(\mathrm{k}, \mathrm{l})$ were generated by technical staff at regular intervals (shown in online suppl. fig. 9). Whereas the smallest string electrodes (a; bare contact length: 1.75 $\mathrm{mm}$, diameter: $0.7 \mathrm{~mm}$ ) produced coagulation volumes down to $18 \mathrm{~mm}^{3}$, rod electrodes (b; contact length: $4 \mathrm{~mm}$, diameter: 2 $\mathrm{mm}$ ) generated coagulation volumes of 200 $250 \mathrm{~mm}^{3}$ [14]. For surgery, stereotactic coordinates were determined for the tip of the carrier probe (a) and the actual target to be reached with the extruded sting electrode (c). The site where the string electrode exits the probe after rotation (b) is indicated (corresponds to angle $\varphi$ at the dial; see fig. 4 and online suppl. fig. 5-7). c, d Electrodes used at the University Hospital Hamburg-Eppendorf until 1994 are demonstrated. The bare tip was even smaller (approximately $1 \mathrm{~mm}$ ).
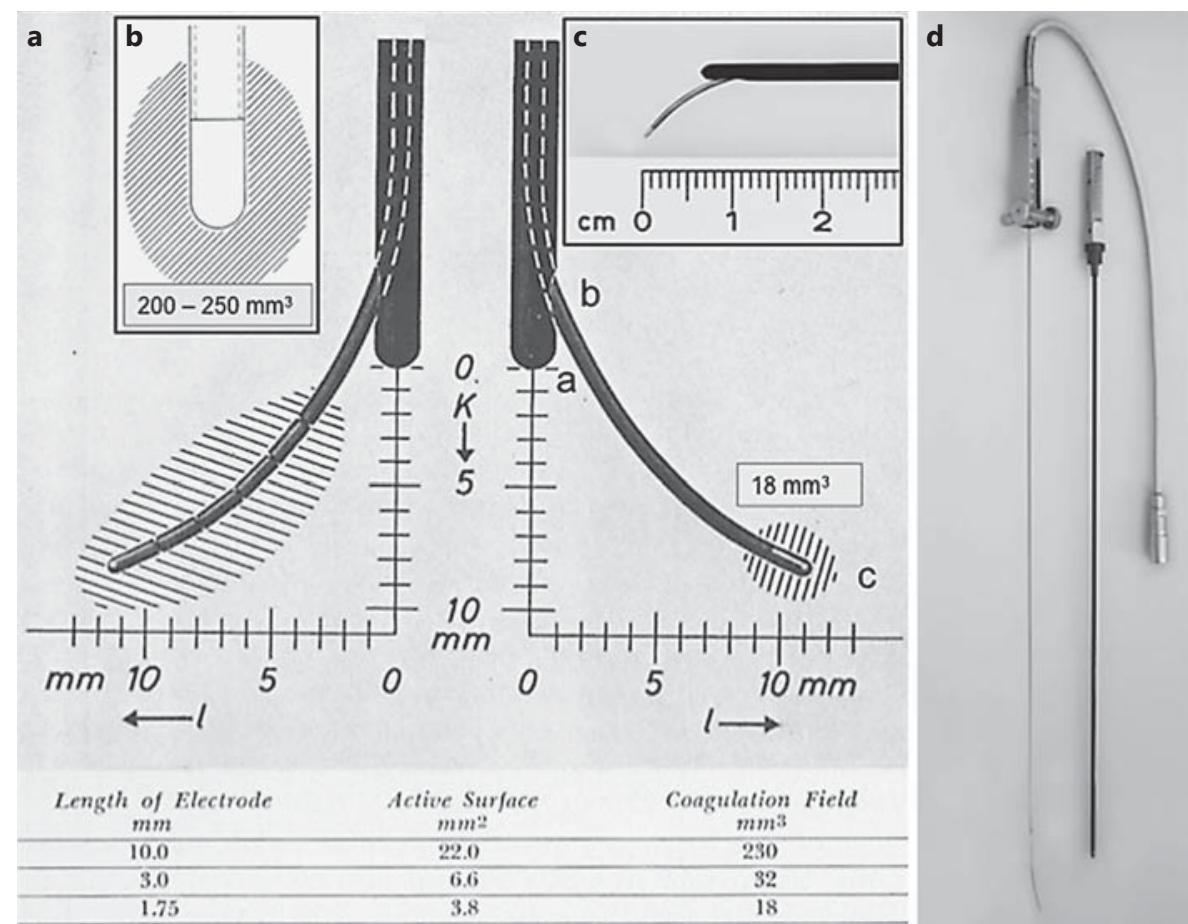

All of this made the procedures time consuming and often lasting into the early afternoon. At an annual meeting of the German Neurosurgical Society the usefulness of these technical refinements had been questioned and regarded as too tedious and not straightforward enough by leading stereotactic surgeons [witnessed by D. Müller, pers. commun.]. Undoubtedly, for busy units performing several such procedures per day the Göttingen approach was impracticable.

\section{Rationale for Choosing String Electrodes}

For several reasons Roeder and Orthner always relied on protruding string electrodes. These were referred to as side electrodes in Göttingen (the German translation for the chord of a string instrument and side is 'Saite' and 'Seite,' respectively) (fig. 3, 4). They emphasized that only these met the requirements for topographically complex deep brain targets. For example, rod electrodes were considered unsuited to deal with the elongated and irregular shape of the pallidum, being also oriented in an oblique way. Furthermore, during test stimulation an electric current can be applied with high precision and at multiple sites, providing higher spatial resolution of the target area and distance from critical structures (e.g. the internal cap- sule or optic tract). Test stimulation to check for side effects was performed according to the pioneering work of Wyss and colleagues [58] using three different parameter settings selected between 1 and $10 \mathrm{~V}$ (usually below $4 \mathrm{~V}$ ) and between 2 and $15 \mathrm{~Hz}$ ( $8 \mathrm{~Hz}$ often proved optimal) applied with a pulse width of $1 / 18 \mathrm{~s}$. Roeder and Orthner used a stimulator with a pulsating direct current and damped oscillations (Wyss stimulator type ST 60; shown in [58]). In addition, using string electrodes it was possible to perform lesions in very small targets (e.g. hypothalamic nuclei). Similarly, microlesioning effects were less and, if these occurred, were attributable to a more confined area. Finally, multiple sites to be lesioned can be reached without inflicting additional trajectories through the patient's brain. In general, multiple small coagulations were strung together to shape a lesion (e.g. seven coagulations in the thalamotomy case presented in online suppl. fig. 5-7). With this method a tailored lesion could be placed even in close vicinity to critical neighboring structures (e.g. optic tract, internal capsule).

For similar reasons Spiegel and Wycis used stylet electrodes that had been developed at the beginning of the 1950 s and resembled string electrodes. However, lesioning based on the use of such stylet electrodes usually involved multiple trajectories $[2,59]$, while the use of the string electrodes allowed complexly shaped lesions to be 


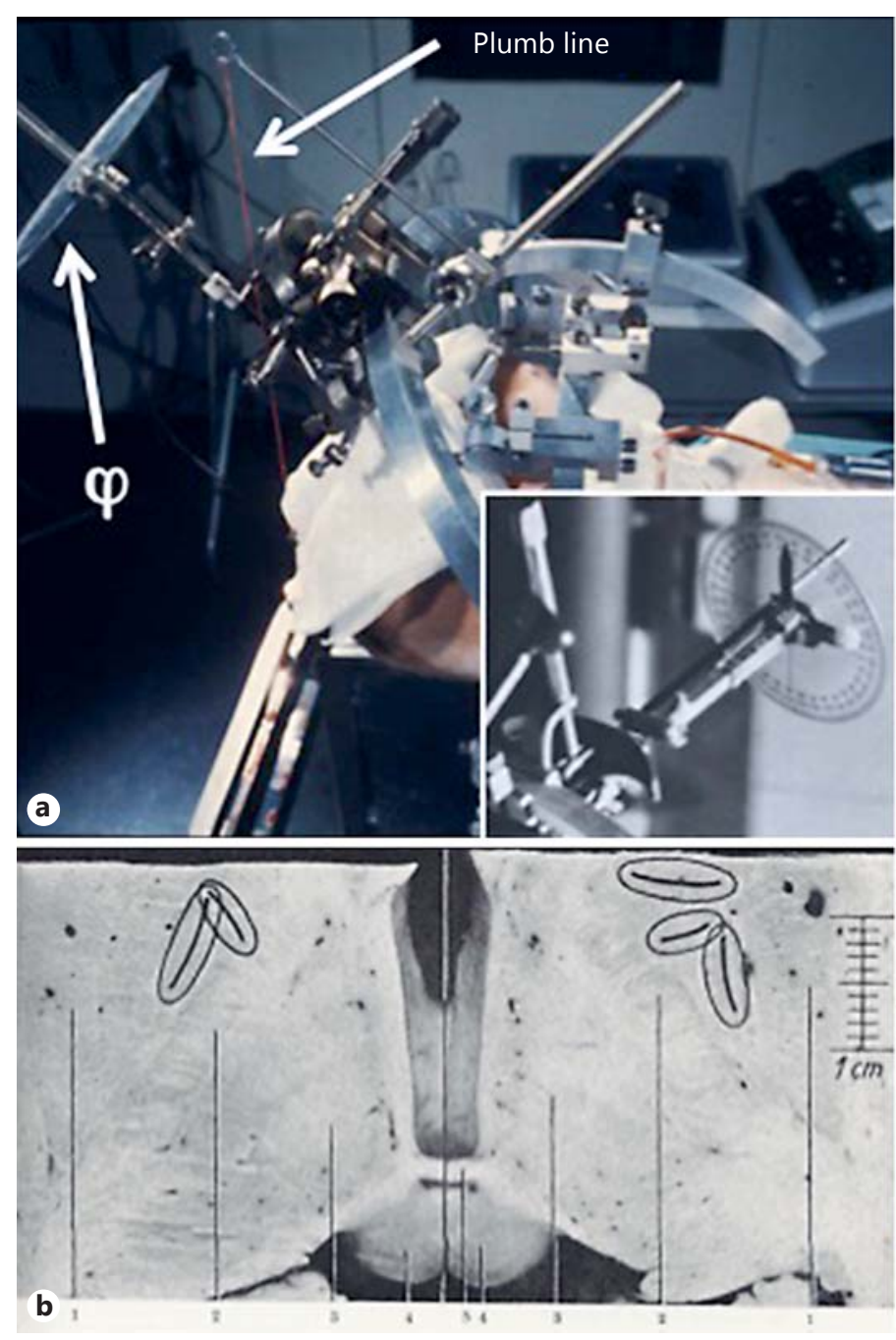

Fig. 4. a Positioning of a patient for stereotactic surgery (8-yearold girl treated at the University Hospital Hamburg-Eppendorf). The dial (magnified in the inserted image) was used to set the direction in which the string electrode was extruded from the rotatable probe (angle $\varphi$; defined in clockwise direction relative to the plumb line). b Outline of a planned lesion for bilateral pallidotomy

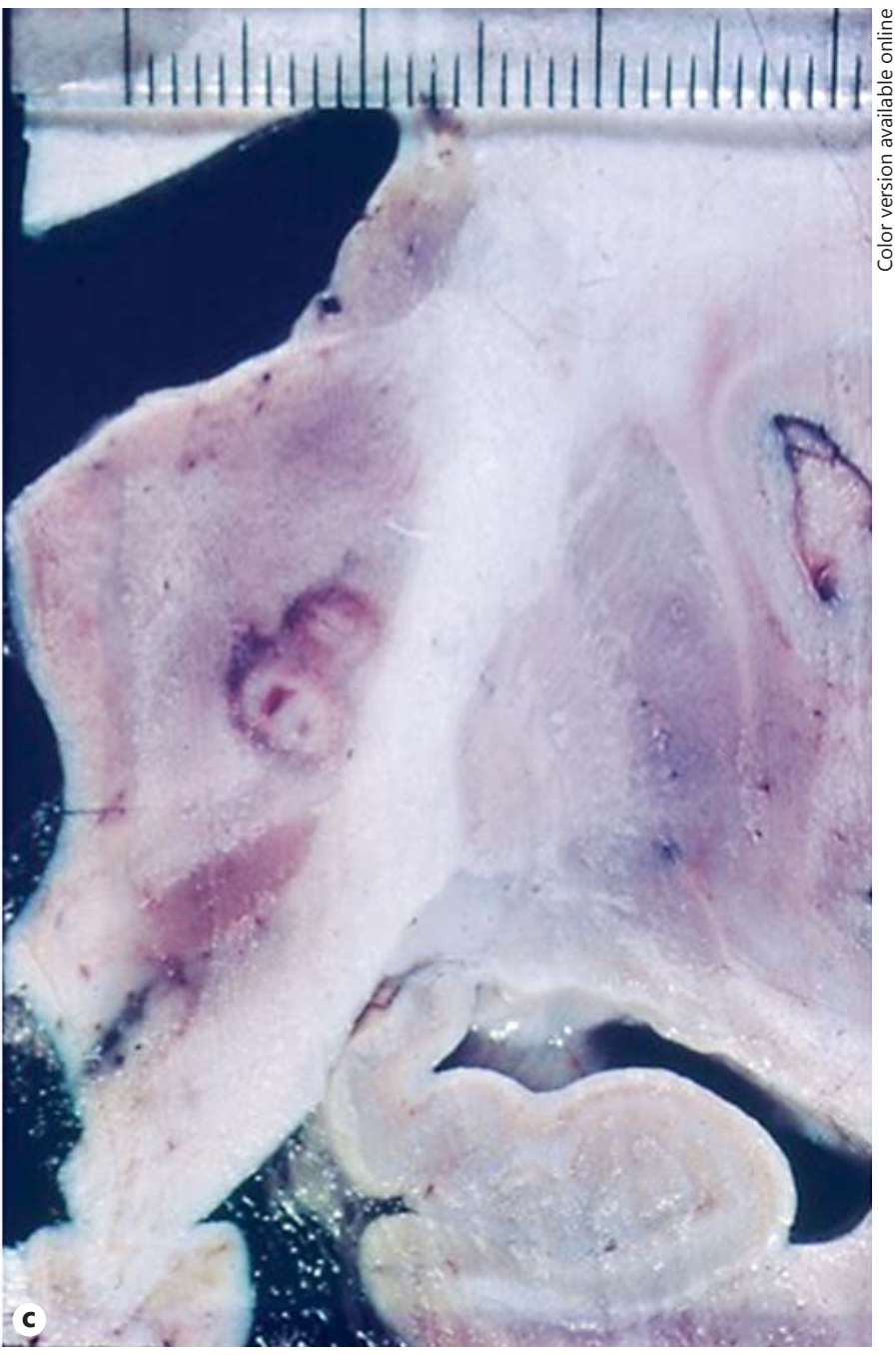

(to be performed in staged procedures). Projection onto an axial slice at the intercommissural $\left(\mathrm{z}_{0}\right)$ plane of a 'model brain' (brain No. 71/57). c Immaculate ventrolateral thalamotomy for torticollis revealing a lesion with a sharp border to the unaffected internal capsule $[14,48]$. Death had occurred 3 weeks after surgery from pneumonia and pulmonary embolism [14]. performed using a single trajectory, avoiding both increased risk of brain movement and hemorrhage. String electrodes were also used in other centers [37,60], but eventually rod (straight needle) electrodes became more popular and have since prevailed. In fact, Roeder and Orthner [3] started using string electrodes developed by Riechert and colleagues in Freiburg [15-17]. They switched to modified electrodes manufactured in the Zentralwerkstatt of the Max Planck Institute, Göttingen, with a gauged driving mechanism and some other improvements [14]. Finally, from May 1961, Roeder and
Orthner used a novel generation of string electrodes featuring insulated tips that had been built by Jenny and Wyss in collaboration with Orthner and Roeder (Department of Physiology, University of Zurich) (fig. 3) [5, 14]. There had been several visits of Roeder and Orthner to Zurich for this purpose (confirmed by D. Müller and A. Orthner). Besides improved mechanical properties (a refined mechanism to drive the electrode and more reliable curvatures), this new electrode was built to refine stimulation and coagulation by allowing more focused test stimulation and more circumscribed lesioning. 
The diameter of this electrode was $0.7 \mathrm{~mm}$, and the uninsulated contact length ranged from 1.75 to $10 \mathrm{~mm}$ (fig. 3). The active surface of a frequently used insulated unipolar side electrode with a $3-\mathrm{mm}$ tip was only 6.6 $\mathrm{mm}^{2}$, which was significantly smaller than the surface of commonly used rod electrodes $\left(25.1 \mathrm{~mm}^{3}\right)$ (fig. 3). The size of single lesions with the insulated electrode ranged, depending on contact length, between $<20$ and $230 \mathrm{~mm}^{3}$, with small tip lesions about 10 -fold smaller compared to rod electrodes, generating lesions of approximately 200 $250 \mathrm{~mm}^{3}$ (fig. 3) [14, 58, 61, 62]. For pallidotomy and thalamotomy, Orthner and Roeder mostly used string electrodes with a contact length of $3 \mathrm{~mm}$ for hypothalamotomy tips of only $1.75 \mathrm{~mm}$ to be able to lesion hypothalamic subnuclei (lesion volume $<20 \mathrm{~mm}^{3}$ ), and for lesions in the frontal white matter and cingulotomy they used multisegmented electrodes with 5 contacts (total contact length $10 \mathrm{~mm}$ ) (fig. 3) [30, 48, 62].

We are not aware of other groups having used this series of insulated string electrodes in patients and who put the same effort into calculating the stereotactic position of the extruded electrode. Notably, these electrodes were not used in Zurich, where these had been originally developed, but eventually string electrodes were considered as needless by Krayenbuhl and Yasargil [63]. However, some years later, Dieckmann, when he was still working in Freiburg, reported on insulated string electrodes with a 2-mm tip that were even equipped with a thermocouple [64]. Prototypes of insulated electrodes had been developed in Freiburg in the mid-1950s as these have been mentioned in a personal letter from Mundinger to Roeder in 1955 (retrieved in the estate of Roeder by C.K.E.M.).

\section{Lesioning}

Roeder and Orthner strongly were opposed to lesioning modes other than radiofrequency thermocoagulation [14]. Brain severing with leukotomes was regarded as too dangerous, especially in the pallidum, known to contain perforating arteries. The instillation of fluids (e.g. alcohol or procaine), radioactive isotopes, cross-beam radiation, or cryolesioning had several disadvantages. Some had to be applied in a repeated manner, some effects occurred with latencies and were difficult to predict, and the rather large, irregular, and often hemorrhagic lesions these methods produced could not be adapted to complex targets, let alone being shaped in an individual manner. Roeder and Orthner remarked that these procedures had been transferred all too soon from animals to humans
[35] which was substantiated eventually by thorough investigations conducted by Gildenberg $[65,66]$.

In their first report [3], probably following Spiegel and Wycis [2], the first (more anterior) pallidotomy was made by multiple electrolytic lesions at different sites with a direct current $(10 \mathrm{~mA}, 1 \mathrm{~min}$ each, the electrode being used as the anode). This method was chosen to minimize heating and to avoid thrombosis; however, it was difficult to control lesion generation. Additional surgery was performed later on the patient, and the second lesion was produced by radiofrequency electrocoagulation. This procedure included 13 thermocoagulations and was performed more posteriorly, including the area of current pallidal targeting. The string electrode developed by Riechert was used [3].

Thereafter, Roeder and Orthner remained committed to thermal lesions elicited by electrical currents applied with a frequency of $500 \mathrm{kHz}$, that is, radiofrequency thermocoagulation. They followed the method described by Hunsperger and Wyss [67] and used their lesion generator 'Coagulateur de Wyss'. Lesions were generated with low currents $(\geq 35 \mathrm{~mA})$. The protocol was worked out in vitro and in animals in collaboration with A.E. Kornmüller (Department of Physiology, Max Planck Institute, Göttingen) in order to prevent extensive heating or even steam-bubble formation (even called 'popping') due to a too quick rise of temperature. This minimized the risk of tissue lacerations by vaporization and explosions which may cause hemorrhages.

Measuring of the temperature at the lesion site can be performed with a thermocouple $[18,64,68]$. This, however, was regarded as too error prone and unreliable, and Roeder and Orthner considered thermocouples as dispensable after they had analyzed their coagulation technique in animals. In addition, thermocouples required the use of thicker probes or additional trajectories, something that they wanted to avoid in order to minimize the surgical risk. Roeder and Orthner did not observe heating along the isolation and concomitant lesioning along the trajectory, which had been a concern of Spiegel $[2,59]$.

\section{Concluding Remarks}

To our knowledge, the widely unknown approach developed in Göttingen by Roeder and Orthner for lesioning in functional stereotactic neurosurgery has to be regarded as one of the most sophisticated and precise to date. In Germany, most influential had been the groundbreaking achievements of Riechert, Hassler, and Mun- 
dinger from Freiburg, who founded one of the first stereotactic centers in the world [reviewed in 69]. Aside from developing a stereotactic system of outstanding accuracy and reliability, they performed pioneering work in functional neurosurgery and neurooncology. Until 1976, the stereotactic center in Freiburg had performed by far the most procedures for neurological and psychiatric indications in Germany, and the Freiburg school of stereotaxy dominated the field [70]. Nonetheless, some attendants of surgical procedures in Freiburg made critical remarks about the accuracy of the staged surgical approach and lumbar encephalography that had been favored in Freiburg until the early 1970s [27, 38].

Although the Göttingen group ranged second behind Freiburg [70], their achievements have remained largely unappreciated and eventually fell into oblivion to the point that the first Göttingen school of stereotaxy is not even mentioned in textbook reviews on the history of stereotactic surgery in Germany [69]. Possible reasons for this are (1) most of the publications from Göttingen were written in German; (2) the group remained small, and only a few fellows were trained (D. Müller was trained by Roeder and Orthner from 1964 until 1972); (3) patient treatment was not performed at an academic institution; (4) the sources for planning (e.g. Orthner's stereotactic brain atlas and spreadsheets) were not available to the community or remained unpopular as most regarded the technique as too laborious and time consuming; (5) the preferred target for Parkinson's disease of the Göttingen school, the pallidum, was abandoned by most peers in favor of the thalamus until the late revival of Leksell's pallidotomy in the levodopa era by Laitinen [71]; (6) Roeder and Orthner trained in neurology, and similarly to Spie- gel, they considered stereotaxy as 'functional neurology', while stereotactic surgery - after the very first pioneering years - rapidly became a pure neurosurgical subspecialty worldwide, and (7) they pioneered ventromedial hypothalamotomy for the treatment of pathological hypersexuality leading to delinquency, which got caught up in a whirlwind of public upset and was dismissed by other medical disciplines eventually, which contributed to an official moratorium of all psychosurgery in Germany, until the era of deep brain stimulation.

The remarkable clinical achievements of the first historical Göttingen group of stereotaxy, accomplished with low rates of complications and proof of extreme accuracy of targeting in autopsy cases, altogether argue in favor of the usefulness of this sophisticated and time-consuming surgical technique in its historical time. Some of the welldocumented clinical achievements have still not been replicated yet even after the advent of modern brain imaging. Clinical outcomes of the Göttingen group therefore also merit a detailed reappraisal that will be reported separately in a subsequent part.

\section{Acknowledgments}

This work would not have been possible without the support, explanations, material, and background information provided by Prof. Dieter Müller. We are indebted to Mrs. A. Orthner, who was involved in the stereotactic calculations and preparation of the brain atlas since 1962, and to Prof. R. Meyermann and Dr. A. Argyrakis, two former fellows of Prof. Roeder and Prof. Orthner, for giving us many invaluable hints and important background information. We thank Frieda Grünhagen for her committed help during the compilation of the cases treated in Hamburg and for entering values from the atlas for the generation of $3 \mathrm{D}$ segmentations.

\section{References}

1 Spiegel EA, Wycis HT, Marks M, Lee AJ: Stereotaxic apparatus for operations on the human brain. Science 1947;106:349-350.

2 Spiegel EA, Wycis HT: Stereoencephalotomy. Part II. New York, Grune \& Stratton, 1962.

3 Roeder F, Orthner H: Erfahrungen mit stereotaktischen Eingriffen. I. Mitteilung. Zur Pathogenese und Therapie extrapyramidalmotorischer Bewegungsstörungen. Erfolgreiche Behandlung eines Falles von schwerem Hemiballismus mit gezielter Elektrokoagulation des Globus pallidus. Dtsch Z Nervenheilkd 1956;175:419-434.

4 Orthner H, Roeder F: Das Parkinson-Syndrom und seine Behandlung durch Elektroko- agulation des Globus pallidus. II. Mitteilung. Stuttgart, Gustav Fischer Verlag, 1959.

5 Orthner H, Roeder F: Experiences with stereotactic surgery. IV. On the long-term effect of bilateral pallidotomy in Parkinson's syndrome (in German). Acta Neurochir (Wien) 1962;10:572-629.

6 Roeder F, Orthner H: Experiences with stereotactic surgery. III. On cerebral surgery of pain with special reference to medical mesencephalotomy in thalamic hyperpathia and anesthesia dolorosa (in German). Confin Neurol 1961;21:51-97.

7 Roeder F, Muller D, Orthner H: Further experiences in the stereotactic treatment of sexual perversions (in German). J Neurovisc Relat 1971;0(suppl 10):317-324.

8 Orthner H: Theoretical and animal experimental bases of anterior hypothalamotomy in the treatment of severe sexual disorder and the accuracy of the method (in German). Fortschr Neurol Psychiatr 1982;50:316-329.

9 Cooper IS, Bravo GJ: Chemopallidectomy and chemothalamectomy. J Neurosurg 1958; 15:244-250.

10 Obrador S, Dierssen G: Results and complications following one hundred subcortical lesions performed in Parkinson's disease and other hyperkinesias. Acta Neurochir (Wien) 1959;7:206-215.
Stereotactic Approach of Roeder and Orthner
Stereotact Funct Neurosurg 2016;94:240-253 DOI: $10.1159 / 000448080$ 
11 Narabayashi H, Okuma T, Shikiba S: Procaine-oil blocking of the globus pallidus for the treatment of rigidity and tremor or Parkinsonism. Arch Neurol Psychiatr 1956;75: 36-48.

12 Aronson NI, Walker AE, McGovern W: A simplified approach to pallidotomy. South Med J 1959;52:136-142.

13 Taarnhoij P, Dolores-Crystal A, Donahue LA: Chemopallidectomy as a treatment for Parkinson's disease: evaluation of results in 118 patients. J Neurosurg 1960;17:459-468.

14 Roeder F: Über die maximale Behandlung des Parkinsonsyndroms. Wiss Beiblatt Mater Med Nordmark 1967;59:1-46.

15 Riechert T, Wolff M: Über ein neues Zielgerät zur intrakraniellen elektrischen Ableitung und Ausschaltung. Arch Psychiatr Nervenkr Z Gesamte Neurol Psychiatr 1951;186:225230.

16 Riechert T, Wolff M: Die technische Durchführung von gezielten Hirnoperationen. Arch Psychiatr Nervenkr Z Gesamte Neurol Psychiatr 1953;190:297-316.

17 Riechert T, Mundinger F: Beschreibung und Anwendung eines Zielgeräts für stereotaktische Hirnoperationen. II. Modell. Acta Neurochir (Wien) 1956;3:308-337.

18 Leksell L: Gezielte Hirnoperationen; in Olivecrona H, Tönnis W (eds): Chirurgie der Hirnnerven und Hirnbahnen. Berlin/Göttingen/Heidelberg, Springer, 1957, vol 6, pp 178-218.

19 Dieckmann G, Schmidt K, Prager J: Positional changes of intracranial structures after encephalography and during stereotaxic operations. Acta Radiol Diagn (Stockh) 1966;5: 644-653.

20 Schmidt K, Dieckmann G, Prager J: On displacements of intracranial structures dependent on location by pneumoencephalography and during stereotactic brain surgery. A contribution to the technic of stereotactic brain surgery (in German). Acta Neurochir (Wien) 1965;13:11-26.

21 Dandy WE: Ventriculography following the injection of air into the cerebral ventricles. Ann Surg 1918;68:5-11.

22 Talairach J: Les explorations radiologiques stereotaxiques. Rev Neurol 1954;90:556-584.

23 Talairach J, David M, Tournoux P, Corredor $\mathrm{H}$, Kvasina T: Atlas d'anatomie stéréotaxique des noyaux gris centraux. Paris, Masson \& Cie, 1957.

24 Redfern RM: History of stereotactic surgery for Parkinson's disease. Br J Neurosurg 1989; 3:271-304.

25 Van Buren JM, Ratcheson RA: Principles of stereotaxic surgery; in Youmans JR (ed): Neurological Surgery. Philadelphia, Saunders, 1973, vol 3, pp 1793-1828.

26 Horwitz NH: Positive contrast ventriculography; a critical evaluation. J Neurosurg 1956; 13:300-311.
27 Levy A: Stereotaxic brain operations in Parkinson's syndrome and related motor disorders. Comparison of lesions in the pallidum and thalamus with those in the internal capsule. Confin Neurol 1967;29:1-70.

28 van Manen J: Stereotactic Methods and Their Applications in Disorders of the Motor System. Assen, Royal VanGorcum, 1967.

29 Calvin TH Jr, Coe JE: Positive pressure ventriculography for stereotaxic surgery. Technical note. J Neurosurg 1967;26:548-552.

30 Orthner H: Sexual disorders; in Schaltenbrand G, Wahren W (eds): Stereotaxy of the Human Brain. Stuttgart, Thieme, 1982.

31 Siegfried J: Die parkinsonsche Krankheit und ihre Behandlung. Berlin, Springer, 1968.

32 Bertrand C, Martinez N: Experimental and clinical surgery in dyskinetic disease. Confin Neurol 1962;22:375-382.

33 Martinez SN, Bertrand C, Botana-Lopez C: Motor fiber distribution within the cerebral peduncle. Results of unipolar stimulation. Confin Neurol 1967;29:117-122.

34 Laitinen LV: Leksell's unpublished pallidotomies of 1958-1962. Stereotact Funct Neurosurg 2000;74:1-10.

35 Orthner H: Stereotaktische Eingriffe im Gehirn. Heidelberger Fortbildungstage 1962. DZK 1963;9:345-359.

36 Fischer HG, Mootschall HJ, Stoffregen J: Data on penthrane inhalation anesthesia with special reference to intracranial operation. Acta Anaesthesiol Scand Suppl 1962;12:56-57.

37 Riechert T: Stereotaxic surgery for treatment of Parkinson's syndrome. Progr Neurol Surg 1973;5:1-78.

38 Laitinen LV: Personal memories of the history of stereotactic neurosurgery. Neurosurgery 2004;55:1420-1429.

39 Mundinger F: Stereotaktische Operationen am Gehirn. Stuttgart, Hippokrates Verlag, 1975.

40 Schaltenbrand G, Bailey P: Introduction to Stereotaxis with an Atlas of the Human Brain. Stuttgart, Thieme, 1959.

41 Edinger L: Ein Hirnmakrotom. Frankf Z Pathol 1907;1:371-372.

42 Jungklaass FK, Orthener H: Quantitative brain research. The method of operation of the Goettinger brain macrotome and photographic documentation of lamellated brain (in German). Zentralbl Allg Pathol 1960;101: 127-138.

43 Amador LV, Brunck HJ, Wahren W: Materials and methods; in Schaltenbrand G, Bailey P (eds): Introduction to Stereotaxis with an Atlas of the Human Brain. Stuttgart, Thieme, 1959, vol 1, pp 3-8.

44 Van Buren JM, Maccubbin DA: An outline atlas of the human basal ganglia with estimation of anatomical variants. J Neurosurg 1962; 19:811-839.

45 Jungklaass FK, Orthner H, Schwerin F: Precision macrotome for use in general brain research (in German). Nervenarzt 1958;29:554.
46 Jungklaass FK, Orthner H: Quantitative Hirnforschung. Die Arbeitsweise des Göttinger Hirnmakrotoms und die photographische Dokumentation des lamellierten Gehirns. Zentralbl Allg Pathol Pathol Anat 1959;101:127-138.

47 Slaughter DG, Bashold BS Jr: A technique for making thin brain slices for stereotaxic measurements. Technical note. J Neurosurg 1968 . 29:302-306.

48 Meyermann R, Müller D, Orthner H, Roeder F: The tremorigenic area of the thalamus. Therapeutic implications in stereotactic neurosurgery of extrapyramidal motor disturbances; in Umbach W, Koepchen HP (eds): Central-Rhythmic and Regulation. Stuttgart, Hippocrates Verlag, 1974, pp 391-396.

49 Jungklaass FK, Orthner H: On quantitative relations in the brain stem: preliminary report (in German). Dtsch Z Nervenheilkd 1960; 181:62-70.

50 Orthner H, Sendler W: Some results of macroscopic-quantitative brain research (in German). Verh Dtsch Ges Pathol 1968;52:243-250.

51 Orthner H, Seler W: Planimetric volumetry of human brains (in German). Fortschr Neurol Psychiatr Grenzgeb 1975;43:191-209.

52 Spiegel EA: Methodological problems in stereoencephalotomy. Confin Neurol 1965;26: 125-132.

53 Mundinger F, Potthoff P: Messungen im Pneumencephalogramm zur intracerebralen und craniocerebralen Korrelationstopographie bei stereotaktischen Hirnoperationen, unter besonderer Berücksichtigung der stereotaktischen Pallidotomie. Acta Neurochir (Wien) 1961;9:196-214.

54 Van Buren JM, Maccubbin DA: A standard method of plotting loci in human depth stimulation and electrography with an estimation of errors. Confin Neurol 1962;22:259-264.

55 Spiegel EA, Wycis HT, Baird HW: Studies in stereoencephalotomy. I. Topical relationships of subcortical structures to the posterior commissure. Confin Neurol 1952;12:121-133.

56 Baird HW 3rd, Chavez M, Adams J, Wycis HT, Spiegel EA: Studies in stereoencephalotomy. Vii. Variations in the position of the globus pallidus. Confin Neurol 1957;17:288-299.

57 Hirabayashi H, Tengvar M, Hariz MI: Stereotactic imaging of the pallidal target. Mov Disord 2002;17(suppl 3):S130-S134.

58 Krayenbuhl H, Wyss OAM, Yasargil MG: Bilateral thalamotomy and pallidotomy as treatment for bilateral Parkinsonism. J Neurosurg 1961;18:429-444.

59 Szekely EG, Egyed JJ, Jacoby CG, Moffet R, Spiegel EA: High frequency coagulation by means of a stylet electrode under temperature control. Confin Neurol 1965;26:146-152.

60 Bertrand G, Jasper H: Microelectrode recording of unit activity in the human thalamus. Confin Neurol 1965;26:205-208.

61 Krayenbuhl H, Yasargil MG: Bilateral thalamotomy in Parkinsonism. J Nerv Ment Disord 1960;130:538-541. 
62 Orthner H, Müller D, Roeder F: Stereotaxic psychosurgery. Techniques and results since 1955; in Hitchcock E, Laitinen L, Vaernet K (eds): Psychosurgery. Springfield, Charles C Thomas, 1972, pp 377-390.

63 Krayenbuhl H, Yasargil MG: Ergebnisse der stereotaktischen Operationen beim Parkinsonismus, insbesondere der doppelseitigen Eingriffe. Dtsch Z Nervenheilkd 1961;182: 530-541.

64 Dieckmann G, Gabriel E, Hassler R: Size, form and structural peculiarities of experimental brain lesions obtained by thermocontrolled radiofrequency. Confin Neurol 1965; 26:134-142.
65 Gildenberg PL: Studies in stereoencephalotomy. X. Variability of subcortical lesions produced by a heating electrode and Cooper's balloon-cannula. Confin Neurol 1960;20:5365.

66 Gildenberg PL: Studies in stereoencephalotomy. VIII. Comparison of the variability of subcortical lesions produced by various procedures (radio-frequency coagulation, electrolysis, alcohol injection). Confin Neurol 1957;17:299-309.

67 Hunsperger RW, Wyss OAM: Quantitative Ausschaltung von Nervengewebe durch Hochfrequenzkoagulation. Helv Physiol Pharmacol Acta 1953;11:283-304.

68 Mundinger F, Riechert T, Gabriel E: studies on the physical and technical bases of highfrequency coagulation with controlled dosage in stereotactic brain surgery (in German). Zentralbl Chir 1960;85:1051-1063.
69 Krauss JK: History of stereotactic surgery in Germany; in Lozano A, Gildenberg PL, Tasker RR (eds): Textbook of Stereotactic and Functional Neurosurgery. Berlin, Springer, 2009, vol 1, pp 53-58.

70 Dieckmann G, Ehebald U, Heimann H, Kockott G, Laschet U, Müller D, Rasch W, Schorsch E, Sigusch V, Venzlaff U: Stereotaktische Hirnoperationen bei abweichendem Sexualverhalten. Abschlussbericht der Kommission beim Bundesgesundheitsamt. Berlin, Dietrich Reimer Verlag, 1978.

71 Laitinen LV, Bergenheim AT, Hariz MI: Leksell's posteroventral pallidotomy in the treatment of Parkinson's disease. J Neurosurg 1992;76:53-61. 